\title{
Conhecimento social em Piaget: um estudo sobre noções de greve
}

\author{
Julise Carvalho Freire'; https://orcid.org/0000-0001-7611-6489 \\ Francismara Neves de Oliveira1'; https://orcid.org/0000-0002-0809-2304
}

\begin{abstract}
Resumo
O estudo investigou a evolução da noção social de greve por meio das significações construídas por alunos de diferentes níveis de escolaridade, tomando-se por base a compreensão de conhecimento social no aporte teórico-metodológico da epistemologia genética. Adotou-se a pesquisa qualitativa, modalidade estudo exploratório, no qual foram empregados entrevista e desenho, apoiados no método clínico-crítico. A amostra configurou-se com 16 alunos, dois de cada série $\left(2^{\circ}, 4^{\circ}, 6^{\circ}\right.$ e $8^{\circ}$ anos do Ensino Fundamental; $1^{\mathrm{a}}$ e $3^{\mathrm{a}}$ séries do Ensino Médio e Ensino Superior $\left(2^{\circ}\right.$ e $4^{\circ}$ anos do curso de Pedagogia). Os resultados revelaram três níveis de compreensão da realidade social. Indicaram que as relações sociais constituem condição necessária, mas não suficiente para o desenvolvimento das noções sociais e que a escola exerce papel fundamental na formação dos sujeitos oportunizando para além do acesso à informação, a construção do conhecimento social.
\end{abstract}

Palavras-chave: Epistemologia genética; construção do conhecimento; greves.

\section{Social knowledge in Piaget: a study of notions of strike}

\begin{abstract}
The study investigated the evolution of the social notion of strike through the meanings constructed by students of different levels of schooling, based on the understanding of social knowledge in the theoretical-methodological contribution of genetic epistemology. We have adopted the qualitative research, exploratory study modality, in which interview and design used, supported by the clinical-critical method. The sample consisted of 16 students, two in each grade (2nd, 4th, 6th and 8th years of elementary school, 1st and 3rd grades of high school and higher education (2nd and 4th year of Pedagogy course). three levels of understanding of social reality. And they indicated that social relations are necessary but not sufficient condition for the development of social notions, and that the school plays fundamental role in the training of subjects, providing access to information, the construction of social knowledge.
\end{abstract}

Keywords: Genetic epistemology; knowledge construction; strikes.

\section{Conocimiento social en Piaget: un estudio sobre nociones de huelga}

\section{Resumen}

En el presente estudio se investigo la evolución de la noción social de huelga por intermedio de las significaciones construidas por alumnos de diferentes niveles de escolaridad, tomándose por base la comprensión de conocimiento social en el aporte teórico-metodológico de la epistemología genética. Se adoptó la investigación cualitativa, modalidad estudio exploratorio, en el cual se empleó entrevista y diseño, apoyados en el método clínico-crítico. La muestra se configuró con 16 alumnos, dos de cada curso $\left(2^{\circ}, 4^{\circ}, 6^{\circ}\right.$ y $8^{\circ}$ cursos de la Enseñanza Básica; $1^{\text {a }}$ y $3^{a}$ cursos de la Enseñanza Secundaria y Enseñanza Universitaria $\left(2^{\circ}\right.$ y $4^{\circ}$ años do curso de Pedagogía). Los resultados apuntaron tres niveles de comprensión de la realidad social. Indicaron que las relaciones sociales constituyen condición necesaria, pero no suficiente para el desarrollo de las nociones sociales y que la escuela ejerce papel fundamental en la formación de los sujetos dando oportunidad para más allá del acceso a la información, la construcción del conocimiento social.

Palabras clave: Epistemología genética; construcción del conocimiento; huelgas.

1 Universidade Estadual de Londrina - Londrina - PR - Brasil; julise_freire@hotmail.com; francis.uel@gmail.com 


\section{Introdução}

O contexto no qual a pesquisa retratada neste artigo teve lugar envolveu a situação recente de greve do funcionalismo público paranaense, na qual profissionais da educação lutavam por melhores condições de trabalho e direitos no conturbado cenário atual da Educação no Estado do Paraná. Opiniões divergentes foram emitidas a respeito do movimento grevista bem como o uso da violência por parte do Estado para conter as manifestações, resultando no que ficou conhecido como o "Massacre dos Professores do Estado do Paraná" e ocorreu na data de 29 de abril de 2015. Pudemos acompanhar o impacto na população, inclusive na comunidade universitária, das informações tendenciosas veiculadas pela mídia. Esse dado nos provocou reflexão e evocou a necessidade de investigar prováveis razões para a ausência de pensamento crítico e contextual acerca dos fatos. Essas experiências motivaram a investigação das significações construídas por alunos acerca do direito de manifestação e greve, à luz do referencial teórico piagetiano.

$\mathrm{O}$ aporte teórico metodológico piagetiano foi eleito por reconhecermos que o método clínico-crítico favorece o tratamento desse problema de pesquisa e por considerarmos que Piaget (1982), em suas entrevistas clínicas, buscava conhecer o pensamento do interlocutor, intervindo de maneira sistemática e, com base nas respostas dadas pelos sujeitos, novas perguntas eram elaboradas, o que permitia, por meio do diálogo, apreender a evolução do pensamento, sua percepção do mundo e a compreensão de noções sociais presentes em seu cotidiano. As pesquisas de Piaget não tratam diretamente da temática supracitada - Direito de Manifestação - porém, suas contribuições referentes à construção do conhecimento social podem ser adotadas na discussão do tema proposto.

As pesquisas realizadas por Jean Piaget (1896-1980) contribuíram para a compreensão de que o conhecimento não está posto, mas que se constitui a medida que o sujeito, ativo em seu processo, se relaciona com outros e atua sobre o mundo ao seu redor. Os postulados estabelecidos no referido campo teórico-epistemológico originaram novas discussões quanto à construção do conhecimento e à compreensão acerca de como se dá o processo de desenvolvimento da inteligência.

Nessa perspectiva, o sujeito é dinâmico, estabelece relações de trocas com o objeto, atuando sobre ele, passando de um estado menor de compreensão, para outro de maior elaboração. A constituição da inteligência, nessa perspectiva, não está determinada pela herança biológica ou hereditária, mas por constantes construções do sujeito, mediante a interação que estabelece com o meio.

No presente artigo, apresentamos os resultados de uma pesquisa que investigou a construção do conhecimento social, considerando a evolução da noção de greve por meio das significações construídas por alunos de diferentes níveis de escolaridade.

O conhecimento é compreendido como resultante de uma construção mais elaborada, não se encontrando pré-formado ou estabelecido no sujeito ou no objeto, nem se originando somente da experiência ou da estimulação advinda do meio, mas, por elaborações, dialeticamente articuladas, visando aprimoramento das estruturas existentes nos mais diferenciados níveis de desenvolvimento.

\section{Piaget e o Conhecimento Social}

Estudiosos contemporâneos vêm realizando pesquisas em torno de distintas temáticas que cercam a vida social; como referência no Brasil destacam-se os estudos de: Almeida (2014), sobre a origem das espécies; Guimarães (2012), que aborda os recursos monetários; Mano (2013), referente à origem da terra e da vida; e Souza e Saravali (2016), a respeito das crenças sobre o não aprender. Tais estudos apontam inúmeras reflexões sobre as mais variadas temáticas que envolvem a vida em sociedade e a relação com o conhecimento social.

Nessa perspectiva o conhecimento social não consiste em uma simples cópia da realidade ou no desdobramento de estruturas pré-formadas. Compreende-se que tanto o conhecimento de outras naturezas quanto o conhecimento social não se encontram em um estágio acabado, mas faz-se necessário que sejam inferidos pelos indivíduos e assimilados às estruturas mentais. Para tanto, a compreensão da realidade social é carregada de subjetivismo, interesses, conceitos que são resultantes de um ativo trabalho individual de reconstrução e reelaboração da realidade (Piaget, 1998).

Para que ocorra a reelaboração da realidade, o sujeito necessita de uma superação lógica, tendo que reelaborar internamente $o$ que $o$ ambiente the oferece por meio dos objetos e das relações com outros sujeitos e com o mundo ao seu redor. Assim, o conhecimento social é a maneira pela qual transformamos os fenômenos sociais em objetos de conhecimento de modo que os conhecimentos são assimilados, interpretados e reorganizados pelos sujeitos, conforme sua própria estrutura. O conhecimento social se integra aos demais conhecimentos em uma relação de codependência, mutualidade e reciprocidade. Nas palavras de Ferreiro (2001):

Piaget opõe uma concepção segundo a qual o objeto não está dado no ponto de partida, mas se constrói a partir de um organismo que não é criado pelo sujeito, mas que é a condição mesma de sua existência; a evidência racional não é produto direto da experiência nem uma forma a priori do espírito: é o resultado de processos de reequilibração sucessivos, em virtude de um processo histórico e dialético; a objetividade não está dada no ponto de partida: é uma realização, uma conquista, não um impor-se do objeto sobre o sujeito, mas um equilíbrio entre ambos, que envolve um máximo de atividade da parte do sujeito, um sujeito que é sempre ator e nunca mero espectador. (p. 138).

Os estudos de Piaget (1998) identificaram que as construções elaboradas pelos sujeitos dependem de todo 
um sistema integrado, considerando que os dados disponíveis no meio social são necessários, mas não são suficientes para elaboração do conhecimento.

Discussões sobre o conhecimento social vêm tomando espaço no Brasil desde o início da década de 90, por intermédio das contribuições de Juan Delval (1989) e demais pesquisadores da temática do conhecimento social na perspectiva piagetiana, em especial: Enesco (1996), Denegri (1998), Baptistella (2001), Tortella (2001), Assis (2003), Stoltz (2005), Costa (2006), Ferreira(2008), Pieczarka (2009), Guimarães (2012), Mano (2013), Monteiro (2013), Almeida (2014), Souza e Saravali (2016), cujas pesquisas versaram sobre as distintas temáticas relacionadas ao cotidiano dos sujeitos.

Os resultados das pesquisas sobre o conhecimento social corroboram com aquilo que a teoria piagetiana acreditava ser o papel ativo do sujeito que conhece. Nessa perspectiva, a construção do conhecimento social passa a assumir uma interpretação diferente, a de que os dados não se impõem, mas são reorganizados, interpretados, o que condiz com os processos de assimilação e acomodação. Portanto, os sujeitos transformam os fenômenos sociais em objetos de conhecimento, dando-Ihes conceitualizações e ideias bastante singulares.

Portanto, os sujeitos, sejam eles crianças ou adultos, não são capazes de reproduzir fielmente as informações que lhe são transmitidas, mas, ao integrar às suas próprias concepções, constroem novos conhecimentos, e nessa nova elaboração, podem ocorrer deformações da realidade. Desse modo, o conhecimento só pode ser construído pelo sujeito por meio das interações sociais nas quais ele se estrutura psiquicamente, socialmente, afetivamente, cognitivamente e moralmente.

\section{Direito de Greve}

Historicamente construído, o direito constitui-se como um fato social e propõe a organização dos comportamentos em sociedade. Nessa perspectiva, o "direito é, por conseguinte, um fato ou fenômeno social; não existe senão na sociedade e não pode ser concebido fora dela" (Reale, 2001, p. 16). O direito constitui-se no seio das relações humanas, com a finalidade de um bem comum, assessorando a regulação do comportamento e desenvolvimento dos sujeitos que vivem em sociedade. A esse respeito, Dimoulis (2011, p. 24) afirma que "o Direito é justo quando protege os interesses gerais da sociedade e, em particular, quando trata de maneira igual as pessoas que se encontram em situação igual".

Uma forma de buscar mudanças na esfera política e de lutar por seus direitos é a greve. O direito de greve é constituído no âmbito coletivo e social, relacionado a reivindicações de melhoria nas relações de trabalho. Em linhas gerais, a greve nem sempre foi um direito reconhecido por lei, mas se constituiu ao longo dos tempos (Silva, 2014). Atualmente, é um direito previsto na Constituição Federal Brasileira de 1988e,em seu art. $9^{\circ}$, é vista como um direito social, a saber: "É assegurado o direito de greve, competindo aos trabalhadores decidir sobre a oportunidade de exercê-lo e sobre os interesses que devam por meio dele defender"(Constituição da República Federativa do Brasil, 1988).

As primeiras greves surgiram em razão das péssimas condições às quais os trabalhadores eram submetidos, com jornadas de trabalho desumanas, excedendo 16 horas diárias, com locais de trabalho impróprios e insalubres, comprometendo não apenas a qualidade de vida, mas também a própria vida do trabalhador (Junior, 2012).

Nos dias atuais e na forma de organização da sociedade civil brasileira, a greve como direito construído no seio das relações sociais é ferramenta de busca de transformações e modificações e envolve as relações trabalhistas em comum. O direito à greve é de extrema importância para a vida em sociedade, pois constituído no âmbito coletivo, dispõe de um diploma legal próprio - a Lei $n^{\circ} 7.783 / 89$.

\section{Metodologia}

Para o desenvolvimento da presente investigação, adotamos a pesquisa qualitativa, na modalidade de estudo exploratório, baseada no método clínico-crítico piagetiano (Piaget, 1982).

A pesquisa qualitativa, segundo Lakatos (2003, p. 186), tem como objetivo “... conseguir informações e/ou conhecimentos acerca de um problema, para o qual se procura uma resposta, ou de uma hipótese, que se queira comprovar, ou ainda, descobrir novos fenômenos ou as relações entre eles".

Neste trabalho, investigamos os níveis evolutivos da noção social de greve em estudantes que cursavam desde o ensino fundamental até o Ensino Superior, em instituições públicas da cidade de Londrina, Paraná. Selecionamos como sujeitos 16 escolares, assim distribuídos: quatro participantes de Ensino Fundamental I (identificados por P1, P2, P3 e P4), quatro do Ensino Fundamental II (P5, P6, P7 e $\mathrm{P} 8$ ), quatro do Ensino Médio (P9, P10, P11 e P12) e quatro do Ensino Superior (P13, P14, P15 e P16), com idades variando entre 7 e 28 anos.

Como instrumentos da pesquisa, apoiada no método clinicocrítico de Piaget (1926/1982), a Entrevista Clínica, foi empregada como principal procedimento de coleta dos dados por meio do qual instrumentos podem ser combinados, a depender dos objetivos e natureza específica de cada estudo. O propósito é desencadear o pensamento do participante acerca de um dado temabem como sua verbalização, para que o pesquisador o acompanhe. Portanto, mais que a resposta do participante, interessa que ele explicite como está pensando (Delval, 2002; Guimarães, 2012, Peralta \& Oliveira, 2017, Oliveira \&Godoi, 2018).

No caso da pesquisa que descrevemos, a Entrevista Clínica foi composta por duas charges sobre as quais se pedia que os sujeitos opinassem, um roteiro de questões norteadoras do diálogo sobre a temática greve para as quai- 
Quadro 1. Resultados e discussões.

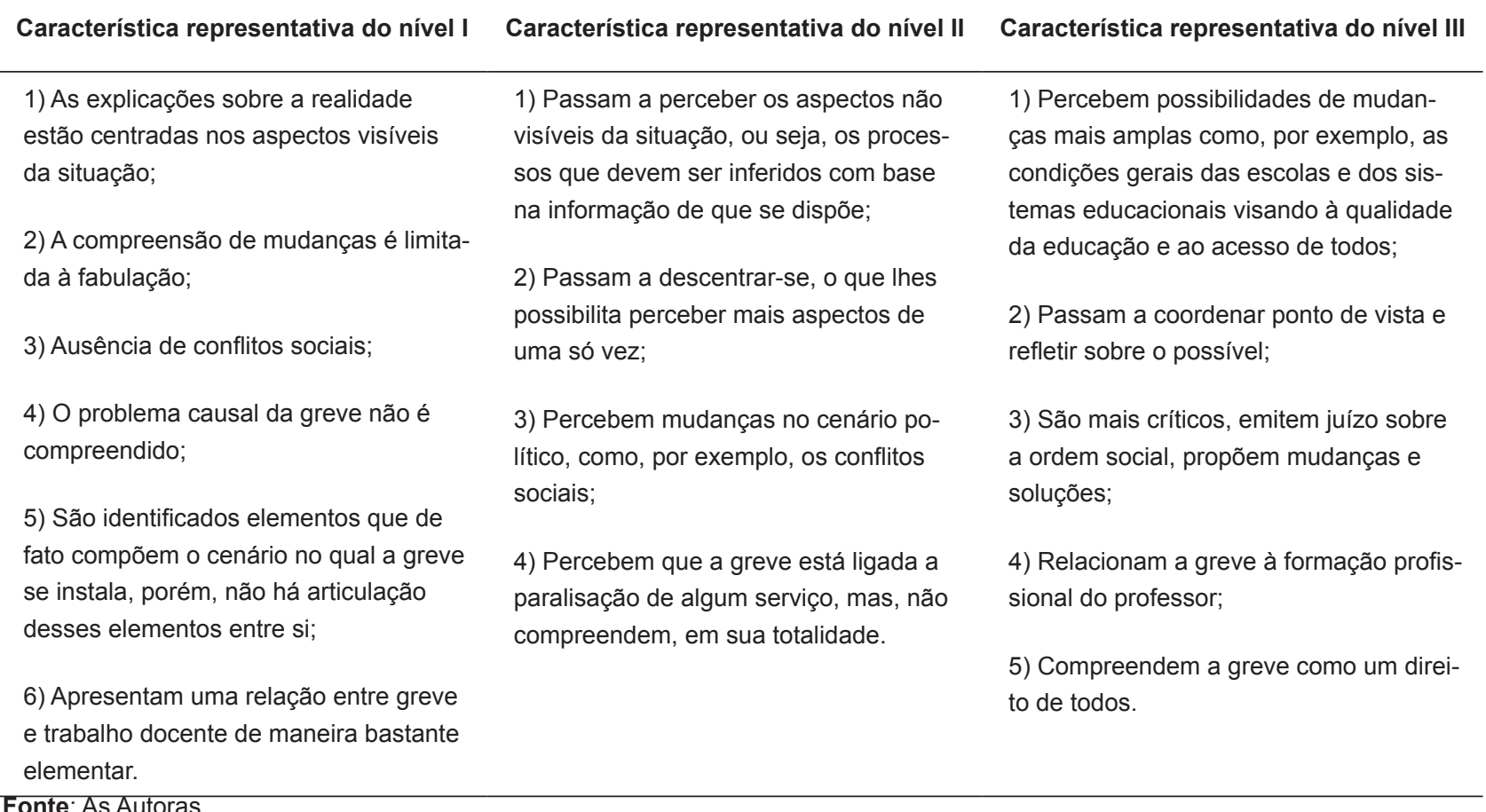

Fonte: As Autoras.

sera sucitada opinião e representação pictórica (desenhos representativos de situações de greve). Esses procedimentos foram adotados para todos os participantes do estudo.

Os elementos obtidos nesta pesquisa, mediante entrevista clínica, que contemplaram as questões e os desenhos, foram analisados em conformidade com os níveis de compreensão da realidade social, identificados por Delval (2002), apresentados a seguir.

\section{Nível I - Noção de Greve}

(P1, 7 anos). Você poderia me dizer o que sabe sobre a greve? A greve é quando os professores param, aí a gente não pode vir, porque não tem aula.Só os professores fazem greve? Não sei. Conte-me o que você acha sobre a greve? Bom, minha mãe me falou que a greve é quando os professores querem ficar de folga um pouco, aí eles param daí a gente não pode vir pra escola. Você saberia me dizer o que acontece quando sua escola não está em greve? Existe alguma diferença de quando a escola está em greve e quando ela não está em greve? Aí a gente estuda, brinca um pouquinho e a gente também pode jogar ali fora na hora da educação física, daí eu e a Carol e uns moleques ficam jogando ali. Você saberia me dizer se a greve é um direito? Não é. Por quê não? Porque aí as crianças e os adultos não podem estudar e ficar inteligente, aí a gente fica pouco tempo no primeiro ano, que a gente aprende a escrever e ler e no segundo ano a gente também aprende isso, daí se eles ficam de greve a gente não pode aprender.

(P4, 9 anos). Conta pra mim o que você sabe sobre a greve. O que eu sei, é que quando os políticos não querem pagar os professores daí os professores vão fazer protesto na frente do negócio dos políticos. E aí tem greve, eu acho que é isso. E é só por conta da falta do pagamento dos professores, ou você acha que fazem greve por outras razões? Eu acho que é por outras coisas. E que outras coisas você acha que é? Pra pedir impeachment da Dilma.
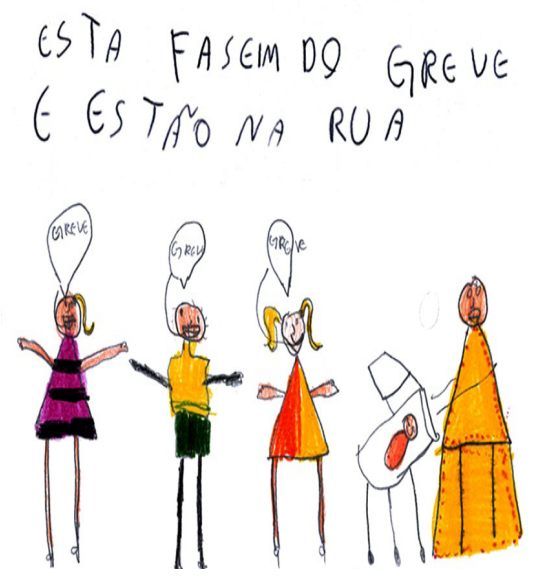

Figura 1. (P1, 7 anos). Fonte: Dados da pesquisa. 


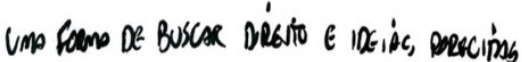

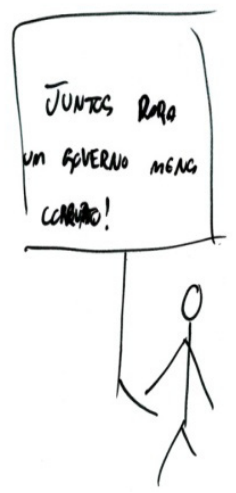

Figura 2. (P4, 9 anos).Fonte: Dados da pesquisa.

As respostas dos participantes identificados neste nível demonstraram que os sujeitos se baseiam nos aspectos mais visíveis das situações. Desse modo, os processos ocultos e subjacentes tão recorrentes nas questões sociais, não são levados em consideração. Além disso, as imagens em que se apoiam os fenômenos sociais apresentam-se bastante estereotipadas e desconectas entre si.

\section{Nível II - Noção de Greve}

(P10, 15 anos). E,em sua opinião, o que é uma greve? É quando um determinado grupo de pessoas, está indignado com uma certa coisa, por exemplo com a corrupção, aí um grupo se reúne e faz um protesto, uma greve, só que muitas vezes eles não se baseiam em fatos científicos, só no senso comum. $E$ quais são os motivos que levam uma pessoa a fazer uma greve? É quando não dá mais para levar ou ir deixando acontecer, é quando está chegando no ponto final e tem que fazer alguma coisa para melhorar. Você já viveu alguma experiência de greve? Só na escola, só que eu não participei, a escola entrou em greve, e eu fiquei em casa e não participei da greve.

(P13, 19 anos). Em sua opinião o que é a greve? Greve é uma reivindicação desses direitos, é uma maneira de cobrar as autoridades cabiveis, pra dizer olha a gente precisa fazer alguma coisa, e o que vocês vão fazer com isso. Em sua opinião, quais os motivos que levam a acontecer a greve? Eu acredito que seja pelo fato desses direitos não estarem sendo garantidos, então, por exemplo, igual às condições mínimas de trabalho, se a gente não tem as condições mínimas de trabalho a gente tem que exigir, a questão salarial, é um direito do professor receber tanto e ele não está recebendo então vamos fazer, é tudo isso que descumpre e fere o direito do profissional. Você já viveu alguma experiência de greve? Conta um pouco para mim. Já, desde que eu entrei na universidade, o ano passado a gente teve aquela greve por conta dessas questões dos direitos que não estavam sendo cumpridos e dos deveres por parte do Estado que deveriam ser cumpridos e não estavam, então nós entramos em greve e foi um clima bem tenso pelas atrocidades acometidas dentro desse processo, e foi gratificante poder participar e dizer eu também estou compactuando com isso no sentido de lutar por aquilo que realmente é de direito para os meus professores e para mim, futura professora, então eu tenho que pensar mais para frente. E quem são as pessoas que podem fazer greve? Todas aquelas que acreditam por algum motivo que seus direitos estão sendo feridos. Então, igual tivemos dois tipos de manifestações, por diversos profissionais, todos os cidadãos foram lutar para ter alguém lá que cumpra com seu papel, e tudo mais, do mesmo jeito que aqui nessa categoria de professores a gente pode fazer isso.

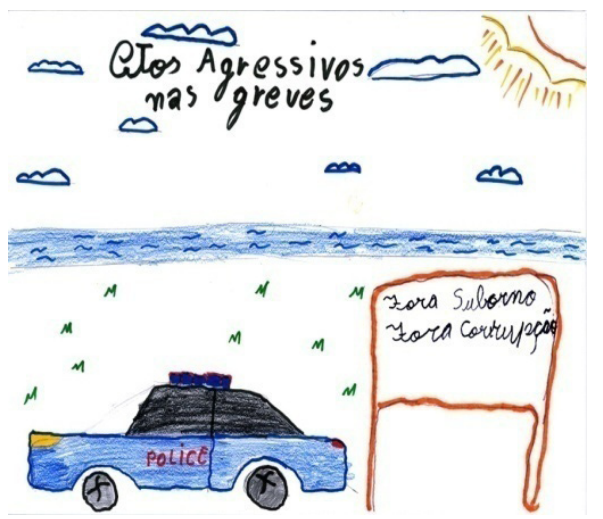

Figura 3. (P10, 15 anos)Fonte:Dados da pesquisa.

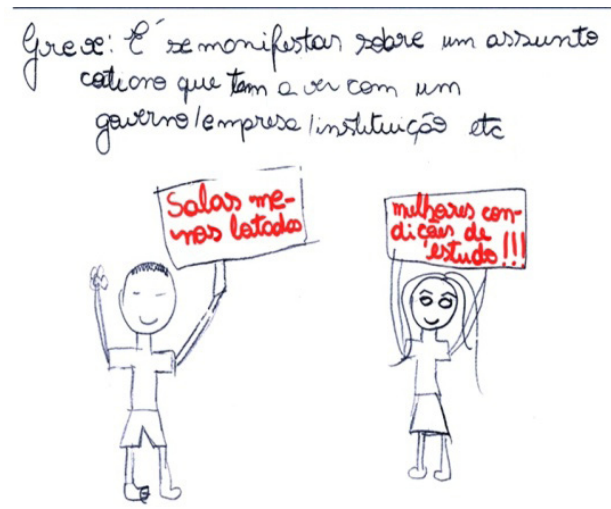

Figura 4. (P13, 19 anos). Fonte: Dados da pesquisa.

(P14, 28 anos). Em sua opinião o que é a greve? É aquilo que eu faço quando meu direito não está sendo cumprido pelo Estado, ou quando o Estado não me dá esse direito. Em sua opinião, quais os motivos que levam a acontecer a greve? É tudo que não está de acordo com que deveria estar previsto na constituição. Por exemplo, professor 
não receber salário, condições mínimas de saúde sendo ofertadas, tudo isso é motivo de greve para mim. Você já viveu alguma experiência de greve? Conta um pouco para mim. Já, aqui na universidade o ano passado quando alunos e professores entraram de greve reivindicando as condições de trabalho do professor em sala de aula, pela condição do aluno enquanto estudante da universidade, então eu participei dos movimentos e sempre que possível eu estava presente.
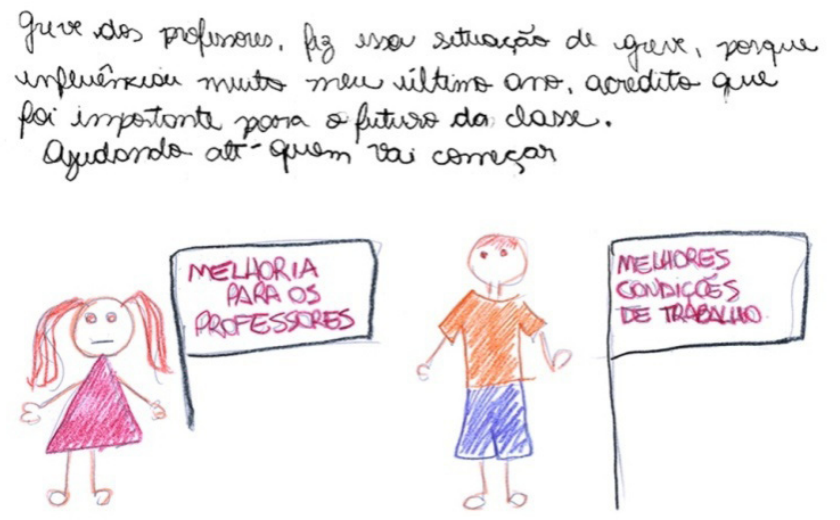

Figura 5. Noção de Greve (P14, 28 anos).

Fonte: Dados da pesquisa.

Neste nível, os aspectos não visíveis dos fenômenos sociais começam a ser levados em consideração pelos sujeitos. Há uma percepção maior dos conflitos, embora a coordenação de diferentes pontos de vista seja algo ainda difícil de ocorrer.

\section{Nível III - Noção de Greve}

As características que compõem o nível III exigem um nível de articulação dialética dos elementos que compõem o fenômeno greve, não o circunscrevendo apenas à relação governo-categoria em greve, por exemplo. A percepção da greve em um cenário sócio-político amplo permitiria respostas de nível crítico sobre a temática suscitada, emitindo juízos sobre fenômenos sociais interdependentes. Os participantes do estudo que apresentamos encontram-se em transição para esse nível, mas ainda não oferecem, em suas respostas, alternativas de modo a integrar e relacionar as informações num sistema mais amplo e coerente.Assim, compreende-se que na investigação realizada não foi possível encontrar respostas características do nível III de compreensão da realidade social no que concerne à temática greve.

\section{Considerações Finais}

$\mathrm{Na}$ pesquisa realizada com crianças, adolescentes e adultos de 7 a 28 anos de idade, foi interessante observar que a construção do conhecimento social, revela níveis diferenciados de compreensão de uma dada noção. No caso desse estudo investigou-se a noção de greve e percebeu-se, diferenças nas explicações do fenômeno social que ratificam a ideia de Piaget $(1970,1976)$ de que os conhecimentos, mesmo aqueles adquiridos nas trocas sociais, são transformados ativamente pelo sujeito não se configurando mera cópia da realidade.

O Conhecimento social, assim como ocorre com o físico e o lógico-matemático em suas especificidades, descreve a construção ativa de processos evolutivos de compreensão gradativa e cada vez mais aprimorada dos modelos de funcionamento social.

No aporte teórico metodológico adotado, o estudo acerca de como se desenvolve o conhecimento social permite compreender os processos evolutivos percorridos pelos sujeitos em seu pensamento, organizando internamente a compreensão dos marcos sociais externosque definem a vida em sociedade, em três âmbitos gerais: normativo-valorativos, informativos e explicativos (Delval, 2018). Assim o conhecimento social é um domínio que permite a evolução da compreensão de noções sociais por meio das quais o real é explicado.

A greve, por exemplo, como direito conquistado socialmente, é garantida pela legislação. Contudo, para que, de fato, os sujeitos compreendam seus direitos e passem a reivindicá-los, faz-se necessária uma construção individual que não advém de fatores biológicos, tampouco exclusivamente da experiência como sujeito. A construção do conhecimento requer ativo processo de significação e reconstrução interna da realidade na qual se está inserido a fim de compreender a greve como um fenômeno social amplo, alinhavado a múltiplos elementos por relações de interdependência.

Por ter sido a greve presente no cotidiano recente dos participantes no momento em que os dados do estudo foram coletados, chamou-nos a atenção o fato de que grande parte das respostas emitidas pelos participantes apresentava ideias bastante elementares, limitadas ao nível I de compreensão da realidade social, enquanto outras localizaram-se em nível II ou de transição, não chegando a alcançar o nível III, considerado mais amplo e mais complexo na análise da realidade.

Ou seja, a análise dos dados nos permitiu constatar que as situações vividas nas relações sociais e as informações delas decorrentes são condição necessária, mas não suficiente para o desenvolvimento da noção social. O conhecimento social resulta de um processo ativo do sujeito que gradativamente aprimora os instrumentos com os quais lê e interpreta a realidade que o cerca. Assim, as explicações dos participantes apresentaram ideias diversificadas sobre a greve porque revelaram processos em construção.Tais processos evidenciaram-se lacunares no que concerne às articulações interdependentes entre elementos que compõem o conjunto de fatores presentes no fenômeno analisado.

No caso deste estudo, as instituições de Ensino Fundamental I e II, Médio e Superior, nas quais o estudo 
se desenvolveu eram públicas e estavam envolvidas no cenário da greve estadual, portanto, os alunos tiveram aulas interrompidas, assistiram a noticiários a respeito da greve, debates foram realizados em sala de aula quando a situação se restabeleceu, alguns participaram das mobilizações durante a greve. Poderíamos ter como resultado que esse cenário seria suficiente para produzir uma análise crítica em níveis mais elevados. Não foi o que os resultados revelaram.

Do mesmo modo, a realidade que nos cerca cotidianamente oferece demandas relevantes para pensarmos e atuarmos em prol da vida em sociedade: processos de humanização, cidadania e solidariedade, qualidade de vida, organização política, social, econômica, enfim, muitas possibilidades de desenvolvimento de noções sociais.

Faz-se necessário favorecer processos de elaboração do conhecimento social de modo crítico, realizando abstrações e generalizações cada vez mais complexas, para que de fato novas construções possam ser realizadas, alcançando assim, níveis mais elaborados de conhecimento social. Nesse sentido, o desenvolvimento cognitivo de nossos alunos, dos nossos adolescentes e jovens precisa ser priorizado nas escolas, pois ele ancora, sustenta o desenvolvimento de noções sociais (Saravali, Guimarães, Guimarães, \& Melchiori, 2013; Godoi, 2018).

A defesa de que o desenvolvimento não se limita a uma simples transferência de conhecimento entre sujeito e objeto, ou entre os sujeitos, mas depende de construções elaboradas na dinâmica das relações, confere à escola um papel fundamental na formação dos sujeitos.

O saber-fazer para dar lugar ao compreender, requer processos de tomada de consciência das ações. Nesse sentido a escola não se limita a espaço de informação, mas principalmente se constitui espaço promotor de construção de mecanismos de ação e reflexão sobre a ação.

Observou-se que dentre os participantes de nosso estudo tivemos inclusive alunos de curso superior, de curso de formação de professores. Formando-se para formar outros. Assim, promover nesses grupos, intervenções que visem o desenvolvimento de níveis de pensamento mais elaborados, parece ser um caminho interessante, considerando-se o efeito multiplicador, quando estiverem em atuação com os alunos na Educação Básica.

Ainda prevalece a escola conteudista e pouco reflexiva, informativa e pouco crítica, tecnológica e pouco analítica, teórica e pouco resolutiva. Essa cisão revela-se socialmente por meio de práticas anti-humanas as quais vivenciamos em episódios sociais e políticos que nos cercam. A escola, como produtora e produto desse cenário social, pode promover práticas reflexivas, promotoras de níveis mais elaborados de consciência social que permitam leitura mais humanizada dos fenômenos e noções sociais.

Por fim, em face da limitação das discussões apresentadas neste artigo, cabe-nos destacar que, em estudos futuros, novos dados podem ser incorporados para validar características de pensamento social, afim de propor processos interventivos que contemplem participantes de diferentes níveis de escolarização em estudantes brasileiros.

\section{Referências}

Almeida, E. A. F. (2014). Pesquisa escolar e sua contribuição para a construção do conhecimento social: Uma pesquisa-ação sobre etnias. Dissertação de Mestrado, Faculdade de Filosofia e Ciências, Universidade Estadual Paulista, Marília-SP.

Assis, O. Z. M. (2003). Conhecimento físico, conhecimento lógicomatemático e conhecimento social. In: Assis, M.; Assis, O. (Orgs.), PROEPRE: Fundamentos Teóricos e prática pedagógica para a educação infantil (pp. 78-104). Campinas: Faculdade de Educação, Unicamp.

Baptistella, E. C. F. (2001). A compreensão do conteúdo de um comercial televisivo na infância. Dissertação de Mestrado, Faculdade de Filosofia e Ciências, Universidade Estadual Paulista, Marília-SP.

Constituição da República Federativa do Brasil. (1988). Brasília: Presidência da República. Recuperado: 5 ago. 2016. Disponível: http://www.planalto.gov.br/ccivil_03/constituicao/ constituicaocompilado.htm

Costa, F. G. (2006). A tomada de consciência e o grupo focal na transformação das representações sócias do envelhecimento: uma pesquisa de intervenção. Tese de Doutorado, Universidade de Brasília, Brasília-DF.

Delval, J. (2002). Introdução à prática do método clínico: descobrindo o pensamento das crianças (F. Murad, Trad.). Porto Alegre: Artmed (Original publicado em 2001).

Delval, J. (2018). La construcción del conocimiento sobre la sociedad. Ensino em Re-Vista, 25(1). Recuperado: 16 mar. 2018. Disponível: http://www.seer.ufu.br/index.php/emrevista/article/ view/41356/21865

Denegri, M. (1998). A construção do conhecimento social na infância e a representação da pobreza e desigualdade social: desafios para a ação educativa. In: Assis, M.; Mantovani de Assis, O. Anais do XV Encontro Nacional de Professores do PROEPRE: A criança e a escola. Campinas: UNICAMP/FE/LPG, pp. 43-54.

Dimoulis, D. (2011). Manual de Introdução ao Estudo do Direito (4a ed.). São Paulo: Revista dos Tribunais.

Enesco, I. (1996). A representação do mundo social na infância. In: Assis, M.; Mantovani, A. O. (Orgs.), Anais do XII Encontro Nacional de Professores do Proepre (pp. 109-122). Campinas: Unicamp, Faculdade de Educação /LPG.

Ferreira, L. M. (2008). Concepção de crianças de 4 a 6 anos sobre o consumo de água: uma abordagem baseada no método clínico, Dissertação - Faculdade de Economia, Universidade Federal de Viçosa, Viçosa - MG.

Ferreiro, E. (2001). Atualidade de Jean Piaget (E. Rosa, trad.). Porto 
Alegre: Artes Médicas.

Godoy, G. A. (2018). A construção de conhecimentos cartográficos e geográficos: um estudo acerca da representação do espaço e sua relação com o conhecimento social na perspectiva piagetiana. Dissertação de Mestrado, Centro de Educação Comunicação e Artes, Universidade Estadual de Londrina, Londrina - PR.

Guimarães, T. (2012). Intervenção pedagógica e noções sobre o meio ambiente: a construção do conhecimento social à luz da epistemologia genética. Dissertação de Mestrado, Faculdade de Ciências e Filosofia, Universidade Estadual Paulista, Marília-SP.

Junior, P. F. F. (2012, setembro). A redução da jornada de trabalho e seus benefícios. Revista Eletrônica do CEMOP, (2). Recuperado: 5 ago. 2016. Disponível:http://www.memoriaoperaria.org.br/ revistaeletronica/paulo_furlan.pdf

Lakatos, E. M. (2003). Fundamentos de metodologia científica (5a ed.). São Paulo: Atlas.

Lei no 7.783 (1989, de 28 de junho). Dispõe sobre o exercício do direito de greve, define as atividades essenciais, regula o atendimento das necessidades inadiáveis da comunidade, e dá outras providências. Brasília: Presidência da República. Recuperado: 5 ago. 2016. Disponível: http://www2.camara.leg.br/legin/fed/lei/1989/lei-778328-junho-1989-372139-publicacaooriginal-1-pl.html

Mano, A. M. P. (2013). Ideias de estudantes sobre a origem da Terra e da vida e suas relações com o desenvolvimento cognitivo: um estudo psicogenético. Dissertação de Mestrado, Faculdade de Filosofia e Ciências, Universidade Estadual Paulista, Marília - SP.

Monteiro, T. A. (2013). A construção da noção de violência em crianças e adolescentes inseridos em diferentes contextos. Dissertação de Mestrado, Instituto de Psicologia, Universidade de São Paulo, São Paulo-SP.

Oliveira, F. N.; Godoi, G. A. (2018). Noções de espaço e lugar na perspectiva de alunos do $6^{\circ}$ ano do ensino fundamental II: relações de interdependência entre conhecimento social e cognitivo. Ensino em Re-Vista, 25(1), 134-158. Recuperado: 16 mar. 2018. Disponível: http://www.seer.ufu.br/index.php/emrevista/article/ view/41363

Peralta, T. P.; Oliveira, F. N. (2017). A relação entre escola e trabalho: a realidade social na perspectiva de crianças e adolescentes. Educação em Questão, 55(45). Recuperado: 16 mar. 2018. Disponível: https://periodicos.ufrn.br/educacaoemquestao/article/ view/12751/8783
Piaget, J. (1970). A construção do real na criança. Rio de Janeiro: Zahar.

Piaget, J. (1976). A equilibração das estruturas cognitivas. Problema central do desenvolvimento. Rio de Janeiro: Zahar, 1976.

Piaget, J. (1982). A representação do mundo na criança. Rio de Janeiro: Difel. (Trabalho original publicado em 1926).

Piaget, J. (1982). O Nascimento da inteligência na criança (4a ed.). Rio de Janeiro: Zahar.

Piaget, J. (1998). Psicologia e pedagogia (9a ed., Lindoso, D. A. \& Silva, R. M. R., trads.). Rio de Janeiro: Forense Universitária.

Pieczarka, T. (2009). Concepções de desigualdade social e mobilidade socioeconômica de adolescentes de escola pública de Curitiba. Dissertação de Mestrado, Universidade Federal do Paraná, Curitiba - PR.

Reale, M. (2001). Lições Preliminares de Direito (25a ed.). São Paulo: Saraiva.

Saravali, E. G.; Guimarães, T.; Guimarães, K. P.; Melchiori, A. P. (2013) Crenças envolvendo o não aprender: um estudo evolutivo sobre a construção do conhecimento social. Educação em Revista, 29(3), 143-176. Recuperado: 13 ago. 2013. Disponível: http://www.scielo.br/scielo.php?script=sci_arttext\&pid=S0102$46982013000300007 \&$ Ing=en\&nrm=iso\&tlng=pt

Silva, O. P. (2014, abril). Greve e ética na Universidade. Estudos Avançados, 28(80), 213-222. Recuperado: 6 ago. 2016. Disponível: http://dx.doi.org/10.1590/S0103-40142014000100018

Souza, E. F. P.; Saravali, E. G. (2016). As relações entre o raciocínio lógico-matemático e a construção do conhecimento social: um estudo evolutivo. Cadernos de Educação, 53, 1-22. Recuperado: 15 dez. 2016. Disponível: https://periodicos.ufpel.edu.br/ojs2/ index.php/caduc/article/view/9155/5958

Stoltz, T. (2005). Mídia, cognição e educação. Educar em Revista, 26(1), 147-156.

Tortella, J. C. B. (2001). A representação de amizade em díades de amigos e não amigos. Tese de Doutorado em Educação, Faculdade de Educação, Universidade Estadual de Campinas, Campinas - SP.

(cc) EY License information: This is an open-access article distributed under the terms of the License (type CC-BY), which permits unrestricted use, distribution and reproduction in any medium, provided the original article is properly cited. 